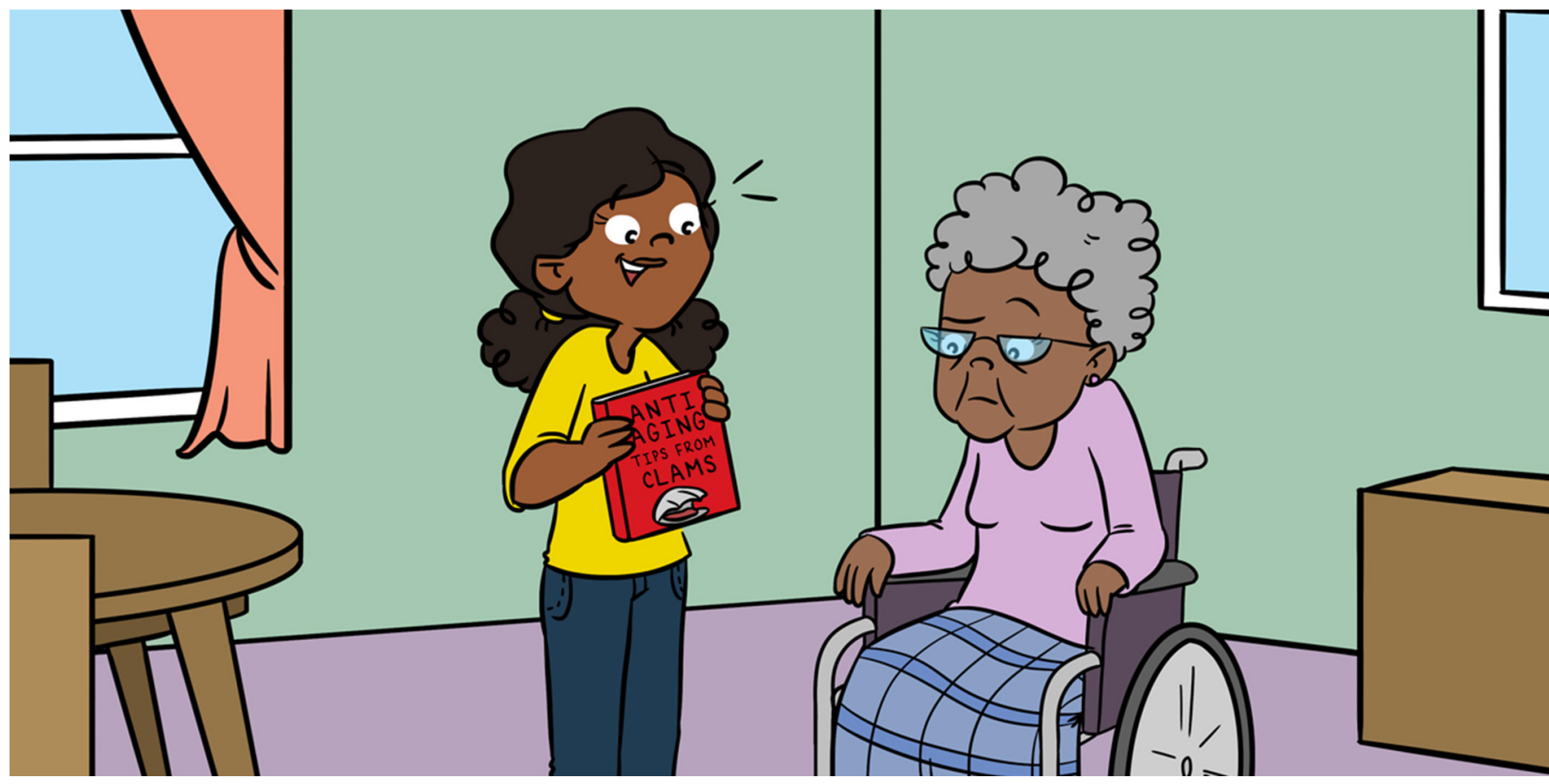

\title{
WHY DO ANIMALS GET OLD AND DIE?
}

\section{André C. R. Martins ${ }^{1 *}$ and Josh Mitteldorf ${ }^{2}$}

${ }^{1}$ NISC - EACH, Universidade de São Paulo, São Paulo, Brazil

${ }^{2}$ National Institute of Biological Sciences (NIBS), Beijing, China

\section{YOUNG REVIEWERS:} KAYSVILLE JUNIOR HIGH AGES: $12-13$ MAREN AGE: 12
As we get old, we become weaker and more vulnerable to diseases. Sooner or later, our health fails, and we die. That happens to most, but not all, animal species. If we want to live longer, understanding why we get weaker is important. Many people work on the question of how aging happens. That is, they try to understand how the cells and living tissues behave as they get older. But there is a deeper question: why do humans and other animals get old at all? Do our bodies just wear out, like old machines? Or is there an important evolutionary reason for getting old? In this article, we will explore those questions. We suggest that getting old and dying serves an important purpose: when the old die, the young can adapt faster to a changing world.

\section{AGING IS NEARLY UNIVERSAL... BUT WHY?}

Almost all animals get old. More importantly, as most animals and humans get really old, they start to get weaker. And, if they live long enough, that weakness will even kill them in the end. Human bodies 


\section{EVOLUTION}

Evolution is the observed fact that living beings who live today are different from those who lived in the past.

That change, that happens slowly over many generations, is what we call evolution.

\section{NATURAL}

\section{SELECTION}

Natural selection is how evolution works. In nature, animals are not all equal. Some are stronger, some are healthier. Those animals that have characteristics that make them more likely to survive are called better adapted. As they are more likely to survive, they leave a larger number of offspring. In the long run, those characteristics that make them better are selected by the competition in nature.

\section{COMMUNITY}

Here, we mean by community, just a group of animals related to each other by family relationships. They might be parents, brothers, cousins, and so on.

\section{ECOSYSTEM}

\section{An ecosystem is a} system that includes all life in one region and all other details of the place. So, the plants, animals, microscopic life, and the terrain in a specific location are all part of the ecosystem in that place. are just not built to live forever. But why not? Maybe we are like furniture. As time passes, a sofa gets damaged and it breaks. But, unlike furniture, living things have built-in repair mechanisms. Some animal species age very quickly and die in less than a day, while others, like some species of jellyfish and clams, seem to never get old. A 100-year-old man has an extremely high probability of dying before his 101st birthday, but a 15-year-old boy can look forward to his 16th birthday. Compare this to clams: a giant 100-year-old clam is actually much less likely to die than a medium-sized 15-year-old clam. Both clams and people suffer damage to their bodies as they age, but clams repair all their bodily damage, while humans only partially repair their damage, so it accumulates. Why do not humans repair all the damage to their bodies, like clams do, and live forever? Is there a bigger reason why most animals get older and weaker and eventually die?

A wise biologist once said, "Nothing in biology makes sense except in the light of evolution." Evolution explains why the animals alive now are much different from those that lived millions of years ago. It explains how sea animals came to land, and how they became dinosaurs, and birds, and monkeys. The idea is simple. Think about all the lions that live in an area. Some are larger, some smaller, some stronger, some faster. They are all different. Some of those characteristics might make it easier for a lion to survive. For example, being fast makes it easier to catch prey. So, the faster lions survive in larger numbers than the slower ones, giving them more time to reproduce. And fast lions tend to have fast cubs so, over time, the lion population as a whole will be faster. The process of selecting a characteristic that makes survival easier is called natural selection. That is how evolution works.

But what about the example of aging? If natural selection favors the animals that stay around longer and produce more offspring, how does getting older and weaker fit in? Should not evolution be using repair mechanisms, like those of the clam, to make animals stronger and stronger, so that they can reproduce more? If staying strong and living longer are better for creating more offspring and passing on genes, why is it that most animals get weaker instead? Why is aging so very common among the animals that evolution has produced it.

\section{INDIVIDUALS VS. COMMUNITIES?}

Being strong and fast is often good for competition between individuals, but "good" can also have a community meaning. All the organisms in an ecosystem must function stably together. Imbalances can spell disaster for every individual, causing whole ecosystems to become extinct.

Let us think about the lions in terms of their broader ecosystem. Why are lions so strong and fast? They need to be fast so they can hunt 
gazelles, their prey. The gazelles in the ecosystem have evolved to run fast to escape the lions, and the lions have evolved to run fast to catch the gazelles. When gazelles evolve to run even faster, lions must also evolve to run faster, or they will starve. When lions evolve to run faster, then gazelles evolve to run even faster, or they will be eaten. Suppose that it is possible for lions to run a little faster than the fastest gazelle. This is great for the individual lions, because they will get enough to eat, and they will produce a bumper crop of lion cubs in the next generation. But it is bad news for the gazelles. In the next generation, there will be more lions and fewer gazelles. And one day, the fast, hungry lions will chase down the last gazelle. The gazelles will disappear from the prairie, and soon after that, the lions will starve.

But suppose the opposite happens: the lions and gazelles both evolve to be fast, but the gazelles are a little faster than the lions. The lions chase the gazelles, but they can only catch the ones that are sick or have some defect. Lions and gazelles form a stable community. The weakest gazelles are the ones that are eaten, so the gazelle herd is kept healthy. The same is true for the lions-the sickly, slow ones will starve. For the whole lion-gazelle system, this seems like a better outcome.

So, for the lion-gazelle relationship, aging helps to make the system stable and robust. Every gazelle eventually gets too old to run fast, so the lions get to eat. And most gazelles can grow and reproduce while they are young and healthy. The way that lions and gazelles have evolved together seems to work well for both, and part because gazelles are strong and fast for a while, and then they get slower and weaker with age. Aging might be part of the recipe for a healthy ecosystem! But does science support the theory that, in the case of aging, natural selection favors the welfare of the whole ecosystem, not just the welfare of the individuals? Keep reading to find out!

\section{PREVIOUS THEORIES OF EVOLUTION AND AGING}

Over the years, evolutionary scientists have come up with two main theories to explain how aging and evolution fit together. In 1957, George Williams proposed that aging is basically a negative side-effect of genes that help us in some way. For example, maybe the same genes that help a young animal to be strong and fertile are pushing the system too hard, and they eventually cause damage. In experiments with fruit-flies and lab worms, scientists found that some of the genes that help animals to be strong and fertile do have harmful side-effects, as the theory predicted. But there are many other genes that increase strength and vitality early in life while also helping an animal to live longer! So this means animals could use those genes to live longer with no bad consequences. That is, the idea that there would be harmful effects is wrong. 
MATHEMATICAL MODEL

A mathematical model is a description of a situation using mathematical tools. It is usually not a complete description, just an approximation. But it can be helpful to teach us why or how things happen.

\section{ADAPTATION}

An adaptation is a characteristic of a living being that allows it to survive better. Getting faster, if it helps lions to survive by catching prey more easily, is one example.
The second theory was that repairing the damage that leads to aging takes energy, and energy must come from food, which can be hard to obtain. So, our bodies must use our energy stores wisely! Using energy for reproduction right away is a "sure thing" for passing on genes, while saving energy now to make repairs to the body in the future is more risky-if an animal chooses to save its energy for later instead of reproducing now, it may not get the opportunity to pass on its genes. This theory made a lot of sense when it was introduced by Thomas Kirkwood in 1977, but a few years later, scientists discovered that when animals have less to eat, they actually live longer! Those facts count against Kirkwood's theory.

Since neither of these theories seems to fully explain how aging might be supported by natural selection, we decided to investigate this on our own. We set about to create a mathematical model to discover how evolution might prefer shorter lives to longer lives. And we thought that, maybe, aging, while it does have a cost, could also provide an advantage by itself.

\section{CHANGE-THE MISSING INGREDIENT!}

Our mathematical model [1] was based on an original idea of André [2], one of the authors of this article. André added a new ingredient to previous mathematical models that had been used to explain the evolution of aging: change. Evolution means change from generation to generation. Animals need to change because the environment is always changing. Characteristics that are good and provide advantages for survival at one moment might fail later when the world is different. And aging helps replace older individuals by new ones, who might be better adjusted to the new circumstances.

We programmed our mathematical model so that every individual has a spot on a game board, as shown in Figure 1. Each square can have only one individual, and the color of the square shows who lives there. Blue squares with sad blue faces represent animals that die from old age. Red squares with red happy faces represent animals that do not suffer harmful effects from age.

When our theoretical animals reproduce, the offspring are born close by. So, when a sad blue face has offspring, a new sad blue face appears somewhere near that parent. That means, after some time, everyone in a local area tends to be related. In nature, resources like food are limited. To represent that, only one individual can survive in each square. When two or more occupy the same space, those individuals compete. And the more capable, better adapted ones have a larger chance to survive. That is the only competition in the game, no individual needs to worry about competition from the other side of the game board. In the long run, some local families tend to spread more than others. In this way, groups of related animals 
Figure 1

Our mathematical model of aging and evolution. The blue boxes with sad faces represent individuals that age, and the red boxes with smiling faces represent those who do not get old. Green squares are empty. Darker shades of blue and red represent individuals who are better adapted. The left figure shows the photo of the board at a given instant and the right figure shows how the same case evolved later in time. We can see the animals who age slowly take the places where those who do not age used to live. As time passes and offspring are created, each group competes for space with others that are close by, and we see that.

\section{FITNESS}

Fitness is just a mathematical number to represent how well-adapted an animal is. It tries to summarize all the complicated details in one number we can understand. The larger the fitness is, the better prepared to survive the animal is.
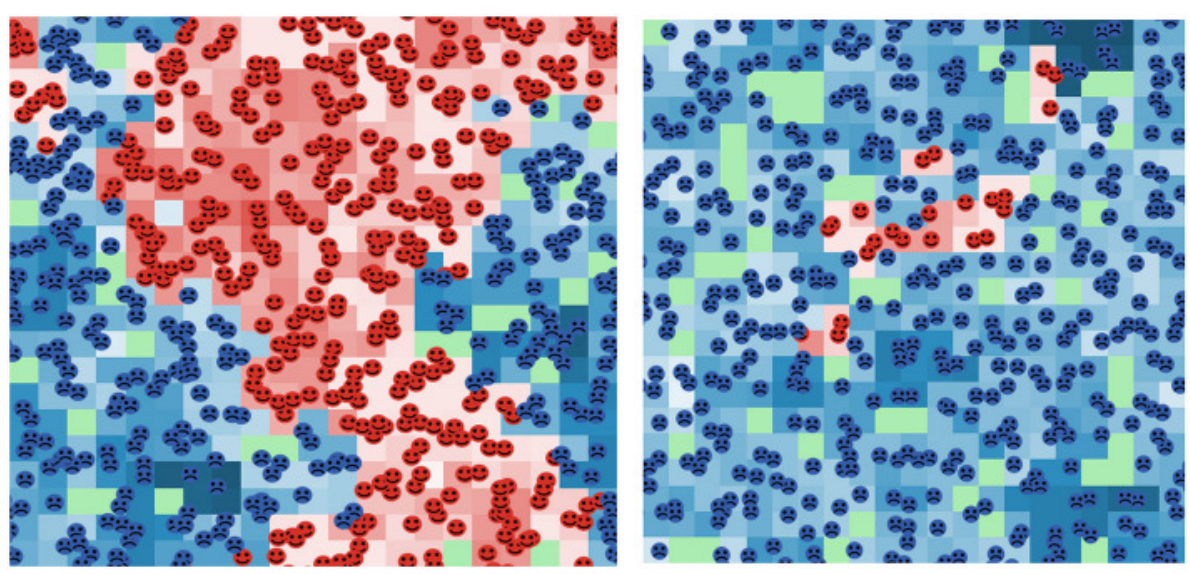

Figure 1

emerged naturally, with boundaries that were irregular and continually shifting. Competitions happens most of the time with animals that are related. That means that those who age tend to compete with those who also age. And aging makes the competition more difficult. It forces the animals to adapt faster. And changing faster is an important advantage.

The need to adapt to a changing environment was an essential factor in our model. Change means what worked before might not work well later. So, we made everyone a bit weaker with time, both those who aged and those who did not. Basically, every animal has a strength associated to it, which we call fitness. Those who have a larger fitness are stronger and have a better chance of surviving when they compete. Also, as in real life, offspring could be born a little stronger or a little weaker than their parents. That is, they might have a fitness that is a little higher or lower than the fitness of their parents. That way, the groups could change and survive. In the game, longer life spans mean older animals will be around longer. The animals get weaker, because the environment in the model is changing at the same time. That means that older animals tend to be the weakest of them. Since the animal communities only change when new animals (which are a little different than their parents) are born, that means that when animals live longer, the group evolves more slowly. A community with a short life span can evolve more rapidly than a community with a longer life span, and therefore can adapt more quickly to the changing environment. Fast-evolving communities soon become better-adapted than slowly evolving ones.

By chance, some had shorter lifespans and others longer. Communities with shorter lifespans evolved faster, producing better-adapted individuals. 


\section{WHAT DO OUR RESULTS MEAN?}

Our mathematical model suggests that maybe we get older because the world changes! Aging can obviously harm individuals, by cutting off their chance to reproduce. But aging might benefit the community as a whole, because aging and death increase the rate of evolution, making populations more adapted to changes in the environment. This could be more important to the health of the overall community than the harm caused by early death. So, maybe aging IS an important process that has been supported by evolution. Sometimes natural selection might prefer a shorter lifespan to a longer lifespan, for the benefit of the whole community!

\section{ORIGINAL SOURCE ARTICLE}

Mitteldorf, J., and Martins, A. C. R. 2014. Programmed life span in the context of evolvability. Am. Nat. 184:289-302. doi: 10.1086/677387

\section{REFERENCES}

1. Mitteldorf, J., and Martins, A. C. R. 2014. Programmed life span in the context of evolvability. Am. Nat. 184:289-302. doi: 10.1086/677387

2. Martins, A. C. R. 2011. Change and aging senescence as an adaptation. PloS ONE 6:e24328. doi: 10.1371/journal.pone.0024328

SUBMITTED: 15 March 2020; ACCEPTED: 30 September 2021;

PUBLISHED ONLINE: 12 November 2021.

EDITED BY: Martha Helena Ramírez-Bahena, University of Salamanca, Spain

CITATION: Martins ACR and Mitteldorf J (2021) Why Do Animals Get Old and Die? Front. Young Minds 9:530721. doi: 10.3389/frym.2021.530721

CONFLICT OF INTEREST: The authors declare that the research was conducted in the absence of any commercial or financial relationships that could be construed as a potential conflict of interest.

COPYRIGHT (c) 2021 Martins and Mitteldorf. This is an open-access article distributed under the terms of the Creative Commons Attribution License (CC BY). The use, distribution or reproduction in other forums is permitted, provided the original author(s) and the copyright owner(s) are credited and that the original publication in this journal is cited, in accordance with accepted academic practice. No use, distribution or reproduction is permitted which does not comply with these terms. 

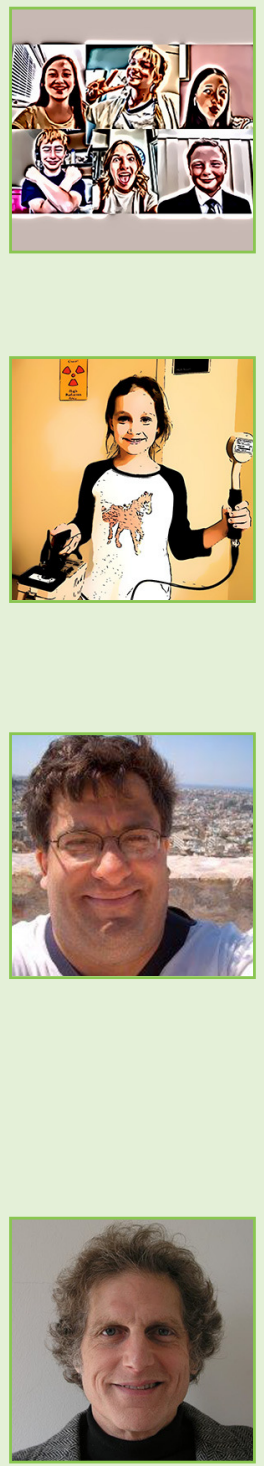

\section{YOUNG REVIEWERS}

\section{KAYSVILLE JUNIOR HIGH, AGES: 12-13}

The students that reviewed this article were selected from Mr. Lanford's Science 7 classes at Kaysville Jr High. Students that live in the area come from strong communities that also know how to appreciate and enjoy nature in the Western US. A lot of the families make a habit to go hiking, fishing, camping, rock hounding, river rafting, biking, and too many other hobbies to mention.

\section{MAREN, AGE: 12}

I am a student who loves to learn, read, and write. I have been playing piano for 7 years and started to play tennis this summer. I like humanities and math at school, and to read books and watch movies at home.

\section{AUTHORS}

\section{ANDRÉ C. R. MARTINS}

I am a researcher of complex systems, studying systems that catch my curiosity, from physics, to how opinions spread, to why we get old. I study situations in which we agree with each other, why we disagree and have extreme views, and how those disagreements can be a problem for scientific practice. I also investigate how simple models of evolution do not tell the whole story. We need more complete descriptions of how animals interact to understand things like aging and cooperation. I am also the father of a 5 year-old boy who loves to learn everything. You can see more about me at www.vieses.com. *amartins@usp.br

\section{JOSH MITTELDORF}

Josh Mitteldorf is an independent researcher and a popular science writer. He has written two books based on his evolutionary theory of aging, and he writes about aging for ScienceBlog.com. In other areas of his life, Josh teaches yoga, plays piano, and writes poetry. He has lived and worked in China, and his two daughters are adopted from there. Earlier in his life, he earned a Ph.D. for his research in astrophysics. If you are curious about what Josh is thinking today, check out Daily-Inspiration.org. 